\title{
Mejí A Fernández, Ricardo. El giro fenomenológico en las neurociencias cognitivas: de Francisco Valera a Shaun Gallagher. Barcelona: Ateneu Universitari Sant Pacià / Universitat Ramon Llull, 2019, 513 páginas
}

\author{
J avier Romero \\ Universidad de Salamanca \\ jromero@usal.es
}

En la siguiente obra, fruto de una investigación doctoral entre España, Francia, Bélgica y Estados Unidos, el doctor Ricardo Mejía Fernández realiza una adelantada incursión sobre uno de los temas filosóficos más aclamados en la actualidad: la relación entre la filosofía y la cognición humana desde los últimos avances en neurociencia. Así pues, la tesis que en este libro se plantea, “El giro fenomenológico en las neurociencias cognitivas: de Francisco Valera a Shaun Gallagher", constituye una contribución mayor sobre las diferentes formas de fenomenología en la actualidad desde una visión actualizada y renovada de la antropología y su relación con las ciencias naturales.

La hipótesis general del autor tiene como uno de sus puntos característicos señalar si se ha producido, o no, un "giro fenomenológico" en las (neuro)ciencias cognitivas $^{1}$, a la luz de las investigaciones del biólogo Francisco J. Valera y del filósofo Shaun Gallagher. Por "giro fenomenológico", una expresión original del autor, Mejía Fernández entiende no la orientación hacia la mente o hacia la conciencia como entidad problemática y de interés por parte de la filosofía o de las

${ }^{1} \mathrm{Al}$ escribir "(neuro) ciencias cognitivas", el autor se refiere tanto a las ciencias cognitivas en general, así como a las neurociencias cognitivas, esto es, a su especificación entre las diferentes disciplinas de la cognición. 
ciencias de la cognición -como por ejemplo se daría en algunos autores como J. Searle-, sino "el viraje excepcional hacia la fenomenología como método complementario de parte, no ya de un filósofo titulado, sino de un renombrado neurocientífico con destacadas competencias filosóficas" (p. 16).

La cuestión que se trata en esta obra no es solventar la entidad de la conciencia, sino llegar a un acercamiento metodológico para responder a su problematicidad desde Francisco J . Valera y Shaun Gallagher. Esta nueva posición distingue acertadamente en dividir la metodología científica y la filosófica, siempre que se realice una continuación de una a otra como presenta el autor mediante una cierta "meta-filosofía" que también es "meta-ciencia".

Partiendo del giro lingüístico aclamado por R. Rorty y también del giro empírico de las ciencias, el "giro fenomenológico" se muestra como un fenómeno histórico, un fenómeno trans-filosófico y trans-científico “que da vuelco a la pretendida impecancia metodológica tradicional de cada disciplina de la cognición a solas" (p. 18). En efecto, el autor señala que es un fenómeno histórico porque puede ser identificado en unos lugares, unas fechas y unos autores determinados; pero también puede clasificarse de fenómeno trans-filosófico y trans-científico "por cuanto nace del derribo de los muros de secesión entre la filosofía y la ciencia", y porque también "nos libera del aprisionamiento en el parcelismo disciplinar que nos encadenaba hasta el momento" (p. 18).

Sin lugar a dudas, Mejía Fernández nos estimula con su prosa al considerar que la ciencia y la filosofía "están hechas por sujetos encarnados", por lo que no existe ni ha existido nunca "la ciencia cristalina ni la filosofía cristalina sin la carne que vivimos y sufrimos" ( p. 18). Frente al pensamiento único en una u otra dirección, en esta obra se plantea pasar desde el tribalismo hacia el pluralismo metodológico para avanzar en la investigación.

Puesto que la neurociencia ve la mente como cerebro, siendo por lo común su metodología primaria el estudio anatómico y fisiológico del cerebro en su estructura y organización elemental, la Parte I de la obra, Los presupuestos del giro fenomenológico: la naturalización (p. 35-150), tiene como punto de partida situar el "giro fenomenológico" en la naturalización, es decir, en una noción previa de naturaleza a partir de Darwin y en una acción naturalizadora particular que precede a todas las investigaciones tanto empíricas como fenomenológicas. Más allá de la naturalización reduccionista de la fenomenología (Dretske, Dennett, Metzinger), una vía intermedia de naturalismo permitiría ir más allá tanto de la 
artificiosa síntesis del fisicalimo neurocientífico como del conservadurismo conceptual filosófico (desde los seguidores de Husserl en adelante), hacia una naturalización común para todos que de "habida cuenta del continuum que es la naturaleza tanto para los científicos como para los filósofos" (p. 39).

Siguiendo estos resultados sobre la naturalización, la Parte II de la obra, La efectuación del giro fenomenológico: Francisco J. Valera (p. 151-356), es clave para entender el núcleo del llamado "giro fenomenológico". El autor realiza un estudio sistemático y pionero sobre la obra del biólogo Francisco J. Valera, cuyo pensamiento sería responsable en gran parte de la efectuación de dicho giro en las (neuro)ciencias cognitivas. Esta parte, como decimos, es nodular puesto que en ella se hallan los contenidos fundamentales por los que dicho giro se materializó históricamente, planteando una remodelación en las (neuro)ciencias cognitivas al uso al prestar una atención particular a la experiencia, esto es, considerar los avances desde la neurofenomenología como exploración metodológica de la experiencia vivida, sin olvidar la herencia del giro valeriano ni las bases neurobiológicas de la neurofenomenología.

Finalmente y en la Parte III, La continuación del giro fenomenológico: Shaun Gallagher (p. 357-456), el autor analiza cómo el "giro fenomenológico" se prolonga en la actualidad en el pensamiento del filósofo Shaun Gallagher, el que fuera codirector de su tesis doctoral. Esta última parte tiene como finalidad complementar lo que el propio Valera, anticipadamente fallecido, no pudo acometer en su neurofenomenología. Gallagher en la actualidad reivindica una fenomenología de carga frontal (front-loaded), propuesta como candidata a seguir pero también enderezar el enfoque de Valera mediante un modelo alternativo que introduzca la fenomenología directamente en el diseño experimental y en diferentes prácticas, como por ejemplo se estaría dando en la actualidad en el marco del proyecto de la NASA sobre "neurofenomenología de la astronáutica" (p. 446456). Además, esta parte serviría para analizar los límites de la neurofenomenología o de la agencia y su aplicación en la fenomenología de carga frontal, entre otras cuestiones, así como enumeraría unas conclusiones generales ( $p$. 457-484) y una bibliografía final.

Debido a la unidad antropológica y fenomenológica de los seres humanos que hacen ciencia y filosofía, la transdisciplinariedad es fundamental en Mejía Fernánez para entender la obra. Sin lugar a dudas, este movimiento de una nueva fenomenología subraya el "realismo especulativo" del Husserl de Investigaciones 
lógicas, así como de otras obras importantes del moravo que valen de eslabón para con la ciencia actual. No obstante, Valera y Gallagher serán para el autor los creadores de una nueva fenomenología empíricamente informada (empirically informed), donde los datos objetivos que confeccionan las ciencias son ininteligibles sin la acción humana libre que valida esta objetivación, ya sea mediante el análisis conceptual lógico, trascendental y/o lingüístico. 